\title{
Preventive Path To Control Fire Accident in Firework Industry using Iot
}

\author{
Kannan Muthuvelu, S. Ramamoorthy
}

\begin{abstract}
The Surveillance and the ongoing examination on Fire work mishaps are just arrangements with the manual preventions, mindfulness and how to keep away from the mishaps during the assembling procedure of wellbeing matches and fireworks. Dangerous mishaps happen frequently, resulting in overwhelming misfortunes of human lives and wounds to laborers. The fundamental driver of Fire mishaps is from Gun Powder. In this Gunpowder not just explosives at the time of higher temperature which additionally obliterated the whole things underneath the referenced temperature. The preventive measure on this surveillance bargains and suggested that the temperature, smoke caution sensor is bolstered to the laborers keep away from heavier harms. The proposed work enhances the preventive system through, advanced IoT based sensors which is deployed on the field to monitor and prevent the real time mishaps. The framework clearly identifies the Automated Chemical Manager (ACM) to balance chemical control activities and threshold limits to avoid the possibility of accidents in the firework industries. The timely alarm through this smart preventive system will avoid the loss of human life and frequent accidents in the firework industry.
\end{abstract}

Keywords: ACM, Gun Powder, Temperature, Smoke Caution, Sensors.

\section{INTRODUCTION}

The aftereffect of examination shows that by and large incidents are realized by an over the top measure of Gun powder contribute at one exertion what's more, accidents coming about as a result of remissness while making fireworks. Risky acts and perilous condition are essential clarification for these disasters. Here some human mix-ups also lead with the incident of the fireworks as seeks after, individuals candling the engineered creations improperly makes a segments between the substances so setbacks will occur in the sparklers invention rooms. Sparklers room won't fittingly use flexible tangle in floors. Most of the working people are not trained and they don't have the foggiest idea about the substance reactions and masterminding exercises so they leave the unused engineered substances in without proper moves. Firework workers contradicts for using metal

Revised Manuscript Received on February 05, 2020.

* Correspondence Author

Kannan Muthuvelu, Department of Computer Science and Engineering, SRM Institute of Science and Technology, Chennai, India.

Email: Kannan.muthuvelu@gmail.com

Dr. S. Ramamoorthy, Department of Computer Science and Engineering, SRM Institute of Science and Technology, Chennai, India. Email: ramamoorthym.s@ktr.srmuniv.edu.in

(C) The Authors. Published by Blue Eyes Intelligence Engineering and Sciences Publication (BEIESP). This is an open access article under the CC BY-NC-ND license (http://creativecommons.org/licenses/by-nc-nd/4.0/) bar, iron shaft. Without tidying up sand materials in readiness room and afterward entering the work sheet. Hardly any individuals hurling cigarette bugs likewise prompts setbacks.

\section{RELATED WORK}

In the here and now putting out flames is an unsafe issue. Various scientists are taking a shot at different strategies for putting out discharge frameworks.

${ }^{1}$ Author Ahmed Imteaj, Tanveer Rahman, Muhammad Kamrul Hossain has propounded system which is capable to detect fire and can provide the location of the affected region. Raspberry Pi 3 has been utilized to control different Arduino which are coordinated with two or three sensors and camera.

${ }^{2}$ Author Divya Pritam has proposed fire identification framework peruses a caught video and concentrates the casing. Each edge is examined for the nearness of fire. Fire is recognized by the nearness of fire pixels in the picture. Fire pixels are distinguished by utilizing the highlights of LUV shading space and half breed changes. The outcome from fire shading recognition and edge location are consolidated. Picture division procedure is applied on the joined resultant picture to section the fire locale from the foundation show the aftereffect of fire recognition.

${ }^{4}$ Author Jayashri M has Engineering for Fire Detection and Prevention in a Fireworks Industry. The Temperature, Moistness and Poisonous and Flammable gases are being detected utilizing the Arduino that is being associated with the bread board that is thusly associated with the cloud server. The Arduino board is remotely associated with the Cloud utilizing $\mathrm{C}++$ code. The information that is being detected is gotten and checked for the limit esteem. In the event that it is more noteworthy than the limit esteem at that point it is advised to the clients by giving SNS.

${ }^{7}$ Author Megha Kanwar has proposed a model to plan an IOT based Fire Fighting Robot which can supplant the conventional Fire Protection Robot. This robot will send a fire caution to the cloud which can be effectively seen through an android application. When the alarm is sent the client can call the programmed beneficiary joined to the robot which will give live spilling video of the fire area, this is conceivable by establishment of an android application at client's end just as for the robot. This collector will likewise fill the need of correspondence of the client with the individuals stuck in the area where fire has happened, along these lines directions on leave courses can be given which is a decent continuous utilization of the model.

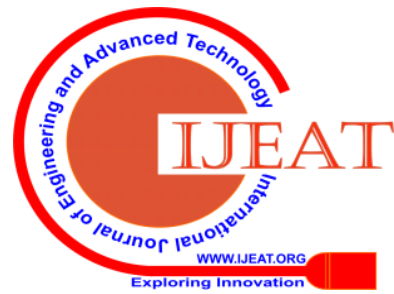




\section{PROPOSED SYSTEM}

To defeat every one of the mishaps that are being occurred in firecracker industry we can actualize a technique called "Robotized Chemical Balance Manager", for staying away from the regular mishaps inside the processing plant. In this strategy propelled sensors and action following framework can be outlined to keep away from debacles.

Rather than offering preparing to uneducated specialists we can show them by increment in Indicators, Buzzers and Fire Alarm sign to caution them. The AI based calculation used to group hurtful compound and hazardous temperature levels. It's likewise important to do compound extents as indicated by area temperature to maintain a strategic distance from fiascos.

\section{PREVENTION TECHNIQUES}

Individuals are not yet taught for anticipation systems utilizing sensors and building applications. Concoction Some manual counteractive action framework that are to be followed in industrial facilities

- Separate places for various kinds of concoction blend for the way toward blending and filling.

- Name sheets for each procedure to be shown.

- Utensils utilized for one kind of blend ought not be utilized for other sort of blend.

- Wear elastic shoes while at work. Try not to convey matches.

- Room will be very much ventilated to diminish the likelihood of residue blast.

- Firework items are never to be hauled generally.

- Fire basins will be loaded up with dry sand.

- All rooms ought to have least of two fire exits.

\begin{tabular}{|c|c|}
\hline Chemicals & Temperature \\
\hline Potassium Nitrate & $129^{\circ} \mathrm{C}$ \\
\hline Sulfur & $190^{\circ} \mathrm{C}$ \\
\hline Aluminium & $600^{\circ} \mathrm{C}$ \\
\hline Antimony & $630^{\circ} \mathrm{C}$ \\
\hline Barium & $550^{\circ} \mathrm{C}$ \\
\hline Calcium & $842^{\circ} \mathrm{C}$ \\
\hline Zinc & $419^{\circ} \mathrm{C}$ \\
\hline Chlorine & $34^{\circ} \mathrm{C}$ \\
\hline Sodium & $350^{\circ} \mathrm{C}$ \\
\hline
\end{tabular}

Table 1: Types Of Chemicals \& It's Temperature

\section{SYSTEM ARCHITECTURE}

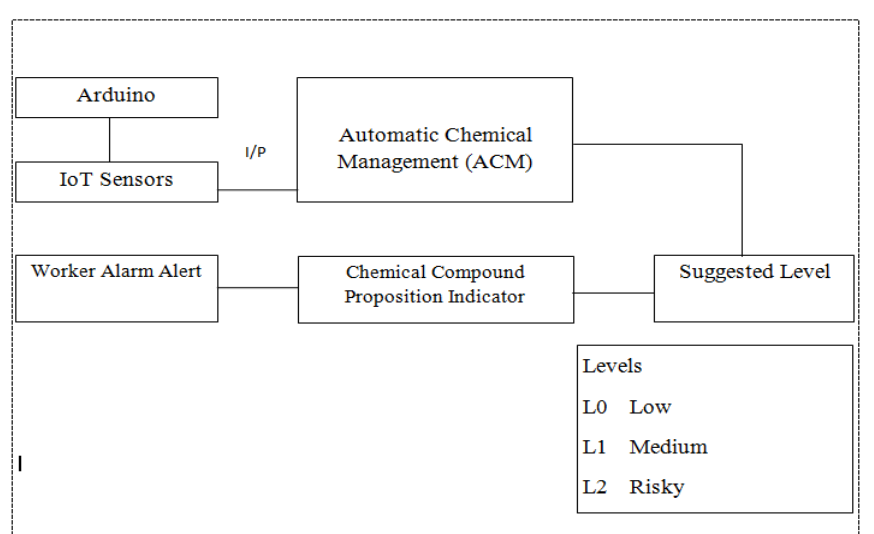

Fig 1: Architecture For Automatic Chemical Manager (ACM) Workflow responses are the primary factor to make the fire hazardous.

\section{A. Information Collection Module Using Sensors}

Sensors will gather area based temperature which is utilized as an Input for ACM compound parity. Sensors are the gadgets which can detect and gives the yield to the client. Various sorts of utilizations require various kinds of sensors to gather information from nature. In an IoT environment two things are significant The Internet and The Physical Devices.

\section{B. Automated Chemical Manager(ACM)}

ACM is a framework, which deals with the whole procedure of synthetic adjusting and blending. ACM is the fundamental unit of preparing i.e., it handles different modules present in it. In this framework the synthetic compounds utilized for setting up a firecracker is finished.

\section{Proposed Levels}

In planning firecrackers levels are significant. In manual arrangement synthetic compounds are filled into the cylinders in enormous amounts which prompts burst out. In computerized framework, levels(L0, L1, L2, L3) are allocated. For every one of these levels certain qualities are appointed with the goal that PC can fill the synthetic concoctions into the cylinders as per the intensity of firecracker.

L0-Low

L1-Medium

$$
\text { L2-High (or) Risky }
$$

\section{Synthetic Compound Proposition Indicator}

In firecrackers planning, numerous synthetic concoctions are filled with the goal that it produces Sound and Various hues. In manual readiness synthetic compounds are blended in enormous amounts without appropriate proportion. Because of different blending of synthetic compounds they get frictioned with one another and burst out happens. In mechanized framework, every one of the synthetic concoctions will be blended in a legitimate proportion as indicated by the present temperature level. Synthetic compounds are blended in enormous amounts. While filling the synthetic concoctions into the containers of a wafer it gets filled by the doled out estimations of every saltine limit.

\section{E. Laborer Alarm Alert}

Caution is essentially a pointer which alarms individuals if there is any hazard in the earth. In this field hazard is all the more so caution is utilized to alarm the representatives. In the event that the measure of warmth is past the edge esteem an alarm is emerges. The warmth worth is detected by the Temperature sensor present in the manufacturing plant.

\section{METHODOLOGIES}

There are various Machine Learning Algorithms which can help the researches to work on with their further research works. These classification algorithms can make the tasks more-easier to work. Here we are using ARTIFICIAL NEURAL NETWORK(ANN) Algorithm.

ANN learning is vigorous to mistakes in the preparation information and has been effectively applied for adapting genuine esteemed, discrete-esteemed, and vector-esteemed capacities containing issues, for example, translating visual scenes, 
discourse acknowledgment, and learning robot control procedures. The examination of fake neural systems (ANNs) has been motivated partially by the perception that organic learning frameworks are worked of exceptionally complex trap of interconnected neurons in cerebrums. ANN framework is inspired to catch this sort of profoundly parallel calculation dependent on dispersed portrayals. By and large, ANNs are worked out of a thickly interconnected arrangement of basic units, where every unit takes various genuine esteemed information sources and creates a solitary genuine esteemed yield. The early model of a counterfeit neuron is presented by Warren McCulloch and Walter Pitts in 1943. A capacity can be portrayed numerically utilizing these conditions

$$
\begin{gathered}
\text { Sum }=\sum^{N_{i=1}} I_{i} W_{i}, \\
y=f(\text { Sum })
\end{gathered}
$$

Where W1,W2,W3... .Wn are weight esteems standardized in the scope of either $(0,1)$ or $(-1,1)$ and related with each information line, Sum is the weighted entirety, and is a limit steady. The capacity $\mathrm{f}$ is a direct advance capacity at the edge.

\section{MULTI LAYER NEURAL NETWORK}

A Multi-Layer Perceptron (MLP) or Multi-Layer Neural Network contains at least one shrouded layers (aside from one info and one yield layer). While a solitary layer perceptron can just learn straight capacities, a multi-layer perceptron can likewise learn non - direct capacities.

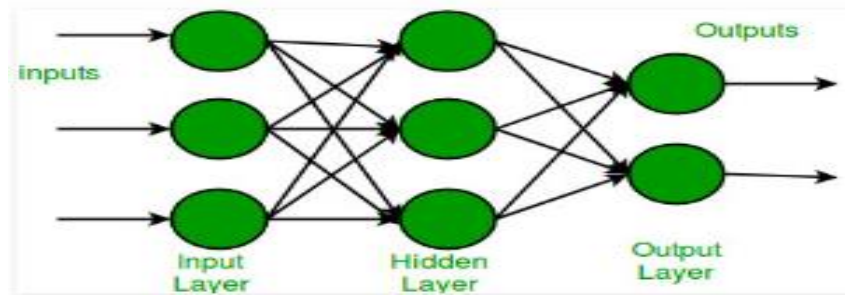

There are three layers present in ANN Multi Layer. They are INPUT Layer, MIDDLE Layer or HIDDEN Layer and OUTPUT Layer. Each of these layers does it's functionalities when the user gives the input and gives back the output.

In our experiment the main idea is to mix the chemicals according to the given threshold value. For a particular variety of cracker combinations of chemicals are used for preparing according to the capacity of cracker.

In ANN method, we input the chemicals in the INPUT Layer. Initially we need to fix the threshold value. With the help of threshold value. he MIDDLE Layer starts processing the mixing part as required. Once the MIDDEL Layer completes its process it produces the output. In case if the chemical levels are more the system alerts like RISKY. The ANN method gives an accurate value which is nearby or matches the given threshold value.

\section{RESULT ANALYSIS}

The various sensors, for instance, Temperature, Flame Detection Sensor and so forth are utilized to recognize the information and gives the reasonable result. The alert will ON when the sensor examines increasingly raised level in temperature and in any occasion, when fire emerges. Smoke area will deliver to Arduino board and range will arise on the LCD.

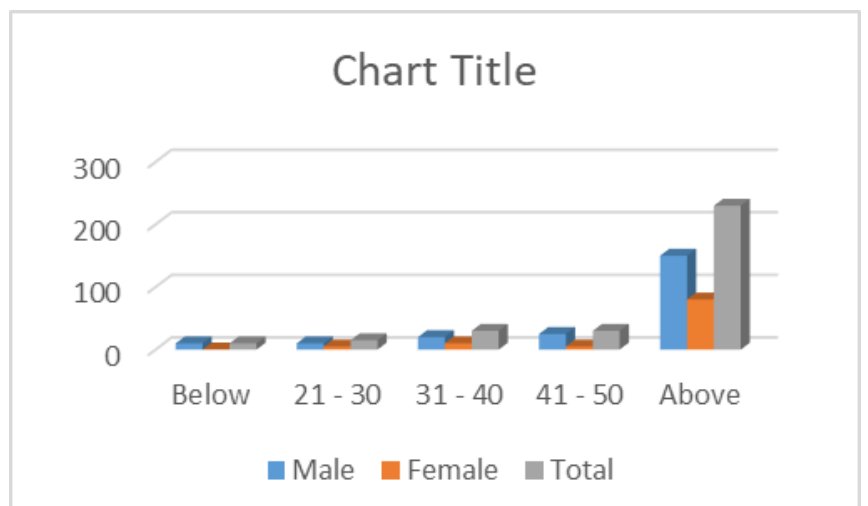

Stream Graph 1: Mishap Overburdened Folk Reliant on the Age and Gender.

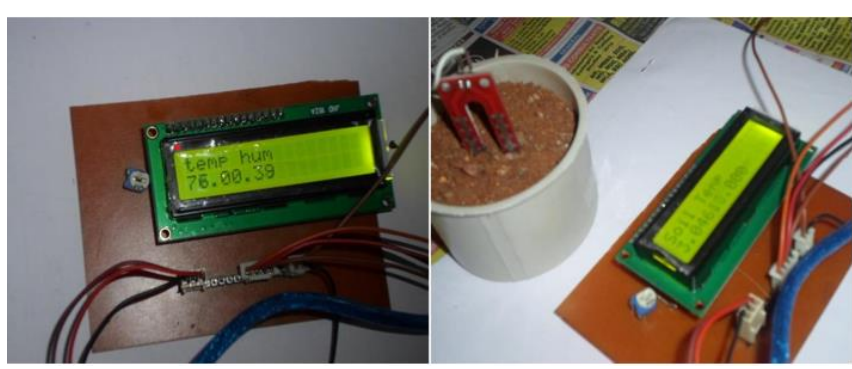

Fig 2: Expose of Checking Climate Dimension and Dimension on LCD

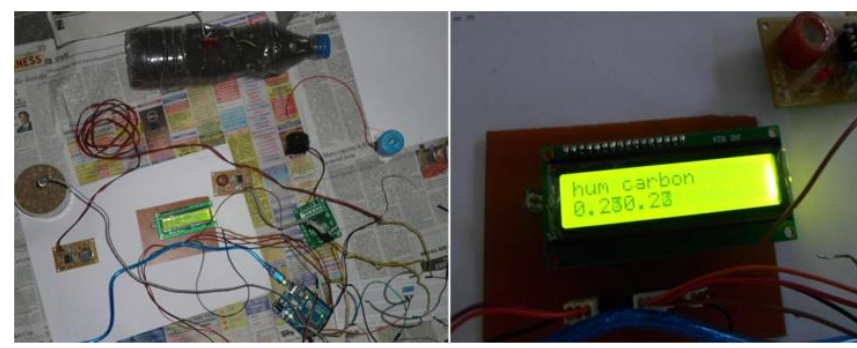

Fig 3: Examination of Expected Framework and to Gauge Carbon Monoxide Extend Show on LCD

\section{CONCLUSION}

The proposed framework is accomplished to our own kin to spare this sort of startling Fireworks mishaps. In this framework we broke down number of synthetic concoctions and GUN POWDER is being utilized. So we can use this framework to spare individuals. Firecracker is a cabin industry. Such a large number of uninformed and unskilled individuals are working in it. In spite of the fact that mindfulness programs are led by the administration, mishaps are occurring a result of their recklessness and their uninformed nature. Laborers are generally not adhering to the guidelines framed by the administration.

In this framework there are certain modules (Suggested Level, Chemical Compound Proposition Indicator) which alarms the representatives during the assembling of saltines. Sensors dispose of the common foundations for mishaps. However, the mishaps are not totally dispensed with the proposed framework will limit the mishaps. 
The fundamental wellspring of salary for these provincial individuals is from the firecrackers processing plants, they are working in a perilous domain. Through our examination we trust it very well may be limited to a limited degree. In this way we guarantee wellbeing for the firecracker assembly line laborers.

\section{REFERENCES}

1. Ahmed Imteaj, Tanveer Rahman, Muhammad Kamrul Hossain, Mohammed Shamsul Alam and Saad Ahmad Rahat, "An IoT based Fire Alarming and Authentication System for Workhouse using Raspberry Pi 3", in IEEE, International Conference on Electrical, Computer and Communication Engineering (ECCE), February 16-18, 2017, Page No 899-904.

2. Divya Pritam, Jaya H. Dewan "Detection of fire using image processing techniques with LUV color space" in IEEE, 2017.

3. Guggilla Anusha, V.R. Seshagiri Rao "Iot Based Ware House Fire Safety System Using ARM7" in IEEE, 2018.

4. Jayashri. M, Newlin Rajkumar. M, Bhuvaneshwari.P "Fire Accidents Detection and Prevention in a Fireworks Industry Using IoT",in IEEE, International Journals of Advanced Research in Computer Science and Software Engineering, March 2019, Volume-9, Issue-3, Page No 67-69.

5. Keerthiga, F.Anishya and R.P.Kaaviya Priya "Accidents Prevention in Industry using IOT" in IEEE, March 2018, Volume 2.

6. Lenin Raja, P.Mariselvam and U.Manimegala "An Innovative Prevention System For Fireworks Raw Material Through Modernized Sensor Technique", in IEEE, International Journal of Environmental Technologies, April 2015, Volume 1, Issue 2, Page No 1-8.

7. Megha Kanwar, Agilandeeswari L "IOT Based Fire Fighting Robot" in IEEE, 2018, Page No 718-723.

8. Palanivelu Rajmohan, P. S. S. Srinivasan "IoT based industrial safety measures monitoring and reporting system using accident reduction model (ARM) control algorithm" in Springer, November 2017.

9. Savitha, Dr.S.Malathi "A Survey on Fire Safety Measures for Industry Safety Using IOT" in IEEE, International Conference on Communication and Electronics Systems, 2018.

10. Zumyla Shanaz F, Prem Kumar S R, Rahul R, Rajesh Kumar M, Santhosh Kumar C "IoT based Industrial Pollution Monitoring System" in IEEE, International Research Journal of Engineering and Technology, March 2019, Volume 6, Issue 3, Page No 2038-2041.

\section{AUTHORS PROFILE}

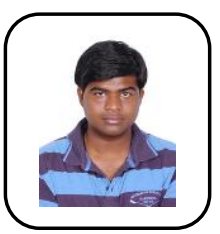

Kannan Muthuvelu, pursuing M.Tech in Compute Science and Engineering, SRM Institute Of Science and Technology, Chennai, Tamil Nadu, India.

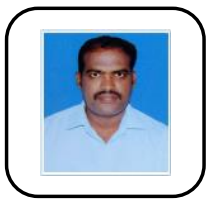

Dr. S. RAMAMOORTHY Associate professor, Department of Computer Science and Engineering, SRM Institute Of Science and Technology, Chennai, Tamil Nadu, India. 